\title{
Regulation of AIF expression by p53
}

\author{
P Stambolsky ${ }^{1}$, L Weisz ${ }^{1}$, I Shats ${ }^{1}$, Y Klein ${ }^{1}$, N Goldfinger ${ }^{1}$, \\ M Oren ${ }^{1}$ and V Rotter ${ }^{*}, 1$ \\ 1 Department of Molecular Cell Biology, The Weizmann Institute of Science, \\ Rehovot 76100, Israel \\ * Corresponding author: V Rotter, Department of Molecular Cell Biology, \\ Weizmann Institute of Science, Rehovot 76100, Israel. Tel: + 9728 9344501; \\ Fax: +972 8 9465265; E-mail: varda.rotter@weizmann.ac.il
}

Received 20.10.05; revised 15.3.06; accepted 30.3.06; published online 26.5.06 Edited by $\mathrm{G}$ Kroemer

\begin{abstract}
The tumor suppressor p53 plays a pivotal role in suppressing tumorigenesis by inducing genomic stability, cell cycle arrest or apoptosis. AIF is a mitochondrial protein, which, upon translocation to the nucleus, can participate in apoptosis, primarily in a caspase-independent contexts. We now report that AIF gene expression is subject to positive transcriptional regulation by $\mathrm{p} 53$. Interestingly, unlike most known p53 target genes, the AIF gene is regulated by basal levels of $\mathrm{p} 53$, and activation of $\mathrm{p} 53$ by genotoxic stress does not result in a substantial further increase in AIF expression. The AIF gene harbors a $\mathrm{p} 53$ responsive element, which is bound by $\mathrm{p} 53$ within cells. p53 drives efficient induction of large-scale DNA fragmentation, a hallmark of AIF activity. Importantly, caspase-independent death is compromised in cells lacking functional p53, in line with the known role of AIF in this process. Thus, in addition to its documented effects on caspase-dependent apoptosis, p53 may also sensitize cells to caspase-independent death through positive regulation of AIF expression. Moreover, in the absence of overt apoptotic signals, the constitutive induction of AIF by p53 may underpin a cytoprotective maintenance role, based on the role of AIF in ensuring proper mitochondrial function.
\end{abstract}

Cell Death and Differentiation (2006) 13, 2140-2149.

doi:10.1038/sj.cdd.4401965; published online 26 May 2006

Keywords: AIF; p53; apoptosis; caspase-independent; mitochondria

Abbreviations: ROS, reactive oxygen species; Apaf1, apoptosis activating factor-1; p53REs, p53 response elements; CIS, cisplatin

\section{Introduction}

The tumor suppressor p53 plays a pivotal role in suppressing tumorigenesis by inducing genomic stability, cell cycle arrest or apoptosis. Wild-type p53 can modulate the transcription of a vast number of target genes that participate in diverse processes, including cell cycle control, apoptosis, senescence, differentiation and DNA repair. ${ }^{1-3}$ p53 was shown to induce apoptosis by the transcriptional induction of a variety of proapoptotic genes, including PUMA, NOXA, BAX ${ }^{4,5}$ and many others. At the cellular level, numerous studies have underscored the crucial role of the mitochondrial pathway (cytochrome $c$ release, reactive oxygen species (ROS) production and mitochondrial membrane potential drop ${ }^{6}$ ) and caspase activation in p53-induced apoptosis. Thus, it has been shown that p53 can induce cell death via a caspasemediated process activated by cytochrome $c$ release and involving apoptosis-activating factor-1 (Apaf1). ${ }^{7}$ However, in the presence of caspase inhibitors, p53 can also act via a delayed onset caspase-independent mechanism, at least in some cell models. ${ }^{8,9}$

Sequence-specific binding of wild-type p53 to p53 response elements (p53REs) within the DNA is essential for its role as a tumor suppressor. The transactivation of different target genes differs: ${ }^{10}$ some genes require high p53 levels, which are induced only upon exposure to p53-activating stress, whereas others are already upregulated by endogenous p53 levels. Most proapoptotic signaling pathways, including those induced by DNA damage, growth factor depletion and cytosolic calcium overload, converge on the mitochondria. Permeabilization of the outer mitochondrial membrane leads to the release of proteins from the intermembrane space. Some of these proteins, including cytochrome $c$, Smac/ DIABLO, Omi/Htra2, AIF and endonuclease G, possess apoptogenic activities that can contribute to both caspasedependent and -independent cell death processes.

AIF is a mitochondrial flavoprotein, which normally resides in the inner mitochondrial membrane and possesses an NADH oxidase activity. ${ }^{11}$ AlF has been proposed to act as a scavenger of ROS, particularly peroxides. ${ }^{12,13}$ However, more recent work has shown that AIF is required for efficient oxidative phosphorylation, most probably through its role in ensuring proper assembly and functionality of mitochondrial respiratory complex 1. ${ }^{14}$ Furthermore, because of this capacity, AIF can exert a cytoprotective role in the mitochondria, enabling cells to cope more effectively with oxidative stress. ${ }^{15}$ Reduced mitochondrial ATP production, as well as specific defects in complex I, is likely to compromise cell viability and render cells more sensitive to the deleterious effects of peroxides and other stress agents. ${ }^{14,16,17}$ In support of a cytoprotective role of AIF in vivo, mice that express reduced AIF levels (harlequin mice) display excessive neurodegeneration, accompanied by signs of chronic oxidative stress. ${ }^{18}$ In fact, cells derived from such mice are highly prone to peroxide-mediated apoptosis, whereas reconstitution of AIF expression protects them from such apoptosis.

Contrasting its cytoprotective role in the mitochondria, translocation of AIF from the mitochondria to the nucleus exerts an opposite effect on cell survival, and serves as a potent proapoptotic trigger. ${ }^{19,20} \mathrm{AIF}$ is believed to induce cell death at least in part by binding to DNA, stimulating DNAse activity and triggering chromatin condensation ${ }^{21}$ and DNA loss associated with large-scale $(50 \mathrm{~kb})$ fragmentation. ${ }^{22}$ Importantly, the various proapoptotic effects of AIF were not inhibited by pharmacological caspase inhibitors such as ZVAD 
or BAF, indicating that AIF can trigger nuclear apoptosis in a caspase-independent manner. ${ }^{23}$ Perhaps not surprisingly, the conserved FAD-binding domain of AIF, required for its $\mathrm{NADH}$ oxidase activity and for its cytoprotective effects, ${ }^{15}$ is dispensable for its proapoptotic function. ${ }^{13,24}$

Thus, AIF has a dual mission in the cell: normally, it resides in the mitochondrial membrane, helps maintain optimal mitochondrial respiratory function and protects cells against the undesirable and eventually deadly consequences of oxidative damage. On the other hand, under conditions of excessive stress leading to mitochondrial dysfunction and culminating in apoptosis, AIF translocates from the mitochondria to the cell nucleus, resulting in large-scale DNA fragmentation. DNA damage in general and cisplatin (CIS) in particular were shown to cause AIF translocation to the nucleus and this translocation was shown to be p53mediated. ${ }^{25}$

We now report that the AIF gene is a transcriptional target of p53. Its expression is positively controlled by basal levels of p53, without much further induction by genotoxic stress. We propose that this fulfills a dual role: in the absence of major stress, the higher constitutive levels of AIF in p53-positive cells equip them with better protection against harmful oxidative damage; however, in response to severe stress, this might predispose them to more efficient death.

\section{Results}

\section{AIF mRNA expression is positively regulated by wild-type p53}

To determine whether AIF expression is regulated by $p 53$, we used several isogenic cell line pairs specifically differing in their p53 status. One such pair consisted of HCT116 human colorectal cancer cells, which possess endogenous wild-type p53, and their p53-/- derivatives in which both p53 loci were somatically partially knocked out, thereby abolishing the production of full-length wild-type p53. As seen in Figure 1a, right panel, real time $\mathrm{RT}$-PCR analysis revealed that parental HCT116 (p53 + / + ) cells contained 2-3-fold higher levels of AIF mRNA than the corresponding p53-/- cells. Interestingly, this pronounced difference was seen already in cells grown under standard tissue culture conditions, and exposure to p53-activating stress (CIS) had only a marginal effect. In contrast, and in agreement with existing knowledge, CIS treatment led to a significant increase in the levels of p21 mRNA (Figure 1a, left panel). Very similar results were obtained when AIF mRNA levels were compared in MCF7 breast cancer cells, which contain wild-type p53, and their derivatives in which p53 expression has been stably knocked down by RNA interference. Here too, the absence of functional $p 53$ resulted in a marked reduction in AIF mRNA, but treatment with the DNA-damaging agent doxorubicin had little effect (Figure 1b, right panel), whereas it clearly increased p21 mRNA (Figure 1b, left panel). Hence, although most of the typical p53 target genes are strongly upregulated by the activated p53 induced by genotoxic stress, our results show that p53 induces AIF independently of DNA-damaging stress.
To rule out the contribution of clonal variation effects to the differences seen in the HCT116 and MCF7-based cell line pairs, we took advantage of an inducible p53 system. This system is based on p53-null H1299 lung cancer cells, expressing exogenous wild-type p53 under the control of the metallothionein gene promoter. Addition of $\mathrm{Zn}^{2+}$ ions to the medium resulted in an increase in p53 mRNA levels peaking within $3 \mathrm{~h}$ (Figure 1c, left panel), which was followed by a gradual increase in AIF mRNA (right panel). Reduced levels of AIF mRNA following p53 inactivation were observed also in two other cell types, WI-38 diploid lung embryonic fibroblasts and LNCaP prostate cancer cells (data not shown). However, in both cell types, the impact of p53 on the basal levels of AIF transcripts was less pronounced than in the cells shown in Figure 1, suggesting that the extent to which p53 controls AIF expression is cell type specific.

\section{Upregulation of AIF protein by wild-type p53}

We next wished to confirm that the effect of p53 on AIF mRNA is also reflected in a specific accumulation of the AIF protein. As seen in Figure $2 a$ and quantified in Figure $2 b$, the basal levels of AIF protein in HCT116 cells were indeed 3-4 times higher than in their p53-/- counterparts. Similar to what had been observed for AIF mRNA, AIF protein levels increased only slightly following stress conditions (middle row), in contrast to the dramatic increase in p53 protein levels (upper row). Similar results were obtained in the comparison of MCF7 cells with their p53 knocked down (p53 RNAi) derivatives (Figure 2a, right panel). Moreover, in the H1299-based inducible p53 system, the increase in AIF mRNA (Figure 1c) was also accompanied by a p53 dose-dependent increase in AIF protein (Figure $2 \mathrm{c}$ ). Thus, basal AIF protein levels are also regulated by wild-type p53, and this is not dependent on further p53-activating stress.

\section{A p53 responsive element resides within an AIF gene intron}

Almost all genes transactivated by $\mathrm{p} 53$ contain one or more p53 responsive elements (p53REs), the sequence of which generally conforms to the consensus defined by el-Deiry et al. ${ }^{26}$ Binding of p53 to p53REs is required for transcriptional activation. To identify potential p53REs, we searched the genomic sequence of the AIF gene and $10 \mathrm{~kb}$ upstream sequences using the 'find-pattern' program. This search yielded several potential p53REs, of which the most promising three, designated p53RE1-p53RE3 (Figure 3a), were chosen for further validation. To test whether any of these putative p53REs could bind p53 in vivo, we performed chromatin immunoprecipitation (ChIP) analysis with MCF7 and HCT116 cells, both of which contain wild-type p53. The precipitated DNA was subjected to PCR amplification using primers specific to each of the three potential p53REs. As seen in Figure 3b, only p53RE3 was found to be associated with p53, implicating it as a functional p53RE. Reduced binding was seen in extracts from MCF7 cells in which p53 had been knocked down (p53 RNAi, p53 Ab; Figure 3b), confirming the specificity of the ChIP process. Interestingly, in line with the 

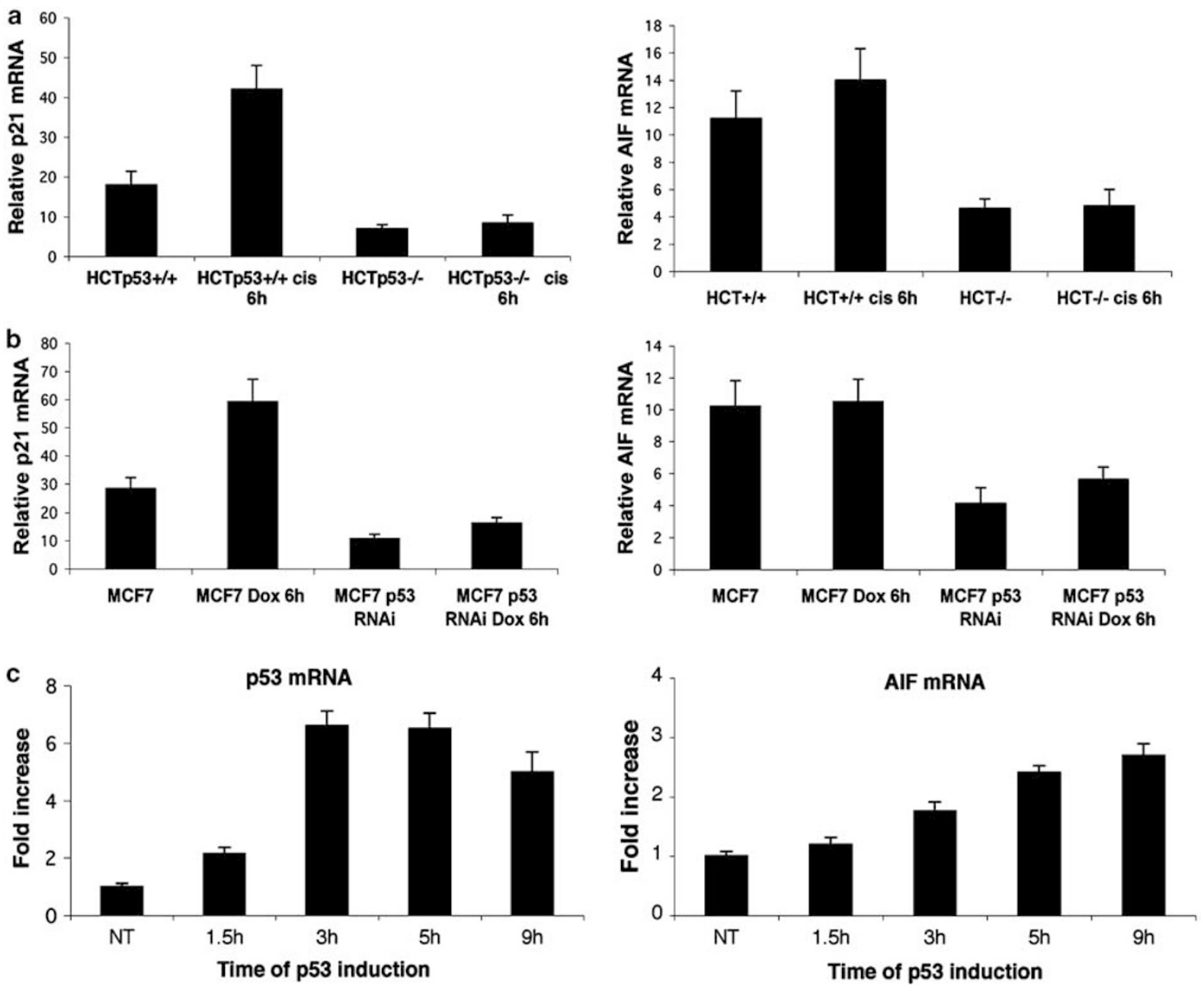

Figure 1 AIF mRNA expression is upregulated by wild-type p53. (a) HCT116 cells, expressing wild-type p53, and HCT116 p53-/- cells were either treated with $5 \mu$ g/ $\mathrm{ml} \mathrm{CIS} \mathrm{for} 6 \mathrm{~h}$ or left untreated. Cells were harvested, RNA was extracted and real-time RT-PCR was performed with primers specific for AIF (left panel), p21 (right panel) or GAPDH as a loading control. Relative levels of AIF and p21 mRNA were normalized to GAPDH expression. (b) MCF7 cells, expressing wild-type p53, and their derivatives in which p53 expression had been knocked down by RNA interference (p53 RNAi), were either treated with doxorubicin (Dox, $0.4 \mu \mathrm{M}$ ) for $6 \mathrm{~h}$ or left untreated. Cells were harvested, RNA was extracted and real-time RT-PCR was performed with primers specific for AIF (left panel), p21 (right panel) or GAPDH as a loading control. Relative levels of AIF and p21 mRNA were normalized to GAPDH expression. (c) p53-null H1299 cells expressing exogenous wild-type p53 under the control of a metallothionein promoter were incubated with $50 \mu \mathrm{M} \mathrm{ZnCl}_{2}$ to induce p53 expression. RNA was prepared at different time points after addition of $\mathrm{ZnCl}$, and levels of p53 (right panel) and AIF (left panel) transcripts were determined by real time RT-PCR. Values were normalized for GAPDH mRNA levels in the same samples, and are shown as fold increase relative to untreated (NT) cells. p53 and AIF mRNA levels are shown before and at the indicated time points after the induction of wild-type p53

fact that AIF expression is not further induced significantly by DNA damage, the binding of p53 to p53RE3 did not increase following exposure to CIS. The p53RE3 site is located within the fourth intron of the AIF gene, about $18 \mathrm{~kb}$ downstream of the transcription initiation site. Although in most known p53 target genes the confirmed p53REs reside at a relatively short distance from the transcription initiation site, the presence of a p53RE at a more distant position is not unprecedented. In fact, recent ChIP analysis of p53 binding along chromosomes 21,22 showed an unexpectedly large number of binding sites, many of which are not in proximity to any known promoters. ${ }^{27}$ Moreover, a functional p53RE located as far as $40 \mathrm{~kb}$ from the transcription initiation site has been shown to regulate the Bnip3L gene. ${ }^{28}$

To determine whether p53 can transactivate gene expression via p53RE3, a $50 \mathrm{bp}$ DNA fragment containing this responsive element (spanning positions 18855-18905) was cloned upstream to an SV40 minimal promoter driving a luciferase reporter gene. Upon transfection into p53-null $\mathrm{H} 1299$ cells, the activity of this reporter was markedly increased in a dose-dependent manner by wild-type p53, but not by the transactivation-incompetent p53 (p53-22,23) mutant or p53(R175 H) DNA-binding domain mutant (Figure 3c, right panel). Moreover, the activity of this reporter was 40 times higher in wild-type p53-containing MCF7 cells than in their isogenic derivatives, in which p53 expression had been knocked down (MCF7 p53i). Furthermore, this activity was increased only slightly following DNA damage, consistent with the conclusion that regulation of AIF mRNA levels by p53 is exerted primarily on basal expression levels, at least under standard tissue culture conditions. These experiments confirm that p53RE3 is indeed a functional p53RE. 
a

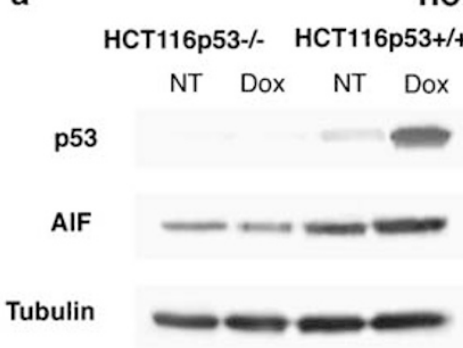

HCT116 cells

HCT116p53-/- HCT116p53+/+ NT cis NT cis

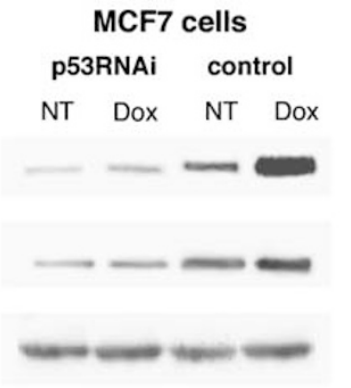

b

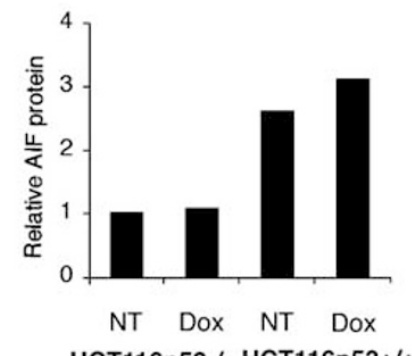

HCT116p53-/- HCT116p53+/+

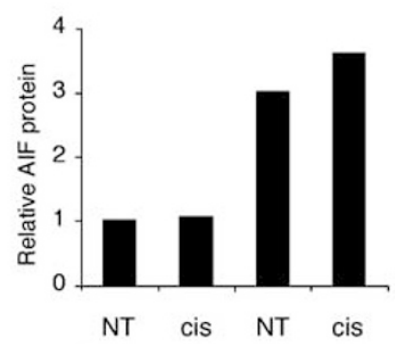

HCT116p53-/- HCT116p53+/+

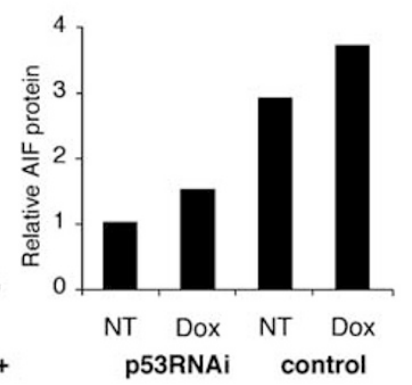

p53RNAI

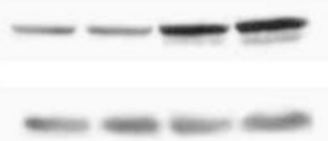

c

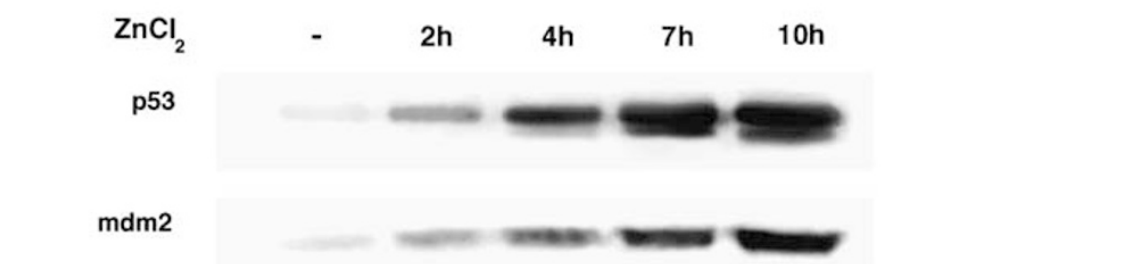

AIF

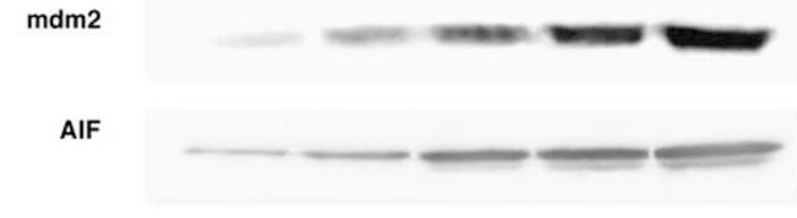

Tubulin

Figure 2 AIF protein is upregulated by wild-type p53. (a) Left: Parental HCT116 cells $(+/+)$ and their p53-/ - derivatives $(-/-)$ were either treated with $0.4 \mu \mathrm{M}$ doxorubicin (Dox) or $5 \mu \mathrm{g} / \mathrm{ml}$ CIS for $12 \mathrm{~h}$ or left untreated (NT). Right: MCF7 cells were compared to MCF7p53 RNAi cells either treated with $0.4 \mu \mathrm{M}$ doxorubicin for $12 \mathrm{~h}$ or left untreated. Cells were harvested, lysed in RIPA buffer and protein levels for each extract were determined by the Bio-Rad protein assay. Equal amounts of total protein from each sample were subjected to SDS-PAGE, followed by Western blot analysis with antibodies directed against p53, AlF or alpha tubulin as a loading control. (b) Quantification of the AIF signals in (a). The bands representing AIF protein were quantified using the 'Image Gauge V3' software. Values are presented as relative AIF protein levels after background subtraction and normalization to the level of AIF in the untreated sample of each group. (c) H1299 cells expressing exogenous wild-type p53 under the control of a metallothionein promoter were incubated with $\mathrm{ZnCl}_{2}$ to induce p53 expression. At the indicated time points, cultures were harvested and equal amounts of total protein from each sample were subjected to SDS-PAGE, followed by Western blot analysis with antibodies against p53, Mdm2, AIF or alpha tubulin as a loading control

\section{p53 promotes AIF activity and caspase-independent cell death}

As discussed above, AIF has been implicated primarily in caspase-independent apoptosis. The ability of p53 to increase AIF levels therefore predicted that p53-mediated apoptosis might possess a significant caspase-independent component, which may be accounted for at least in part by AIF. We therefore assessed the effect of zVAD-fmk, a broad-spectrum caspase inhibitor, on the death of cells differing in p53 status. As seen in Figure 4a, induction of p53 expression in $\mathrm{H} 1299$ cells by addition of $\mathrm{Zn}^{2+}(\mathrm{H} 1299 \mathrm{i}+\mathrm{Zn})$, even without any further DNA-damaging treatment (NT), led to a marked increase in cell death. The extent of cell death was further increased when the cells were exposed to CIS, where a substantial p53-independent component also became apparent. Of note, although zVAD-fmk reduced overall p53dependent cell death in both non-treated and CIS-treated cells, many cells nevertheless continued to die even in the presence of the caspase inhibitor. This strongly supports the notion that, at least in this cellular system, p53-mediated cell death occurs through a combination of caspase-dependent and caspase-independent mechanisms. One distinctive hallmark of AIF nuclear translocation is the induction of largescale $(50 \mathrm{~kb})$ DNA fragmentation. We therefore wished to determine whether the increased levels of AIF protein in p53positive cells are associated with higher AIF activity when such cells are induced to undergo apoptosis. To that end, p53 
a

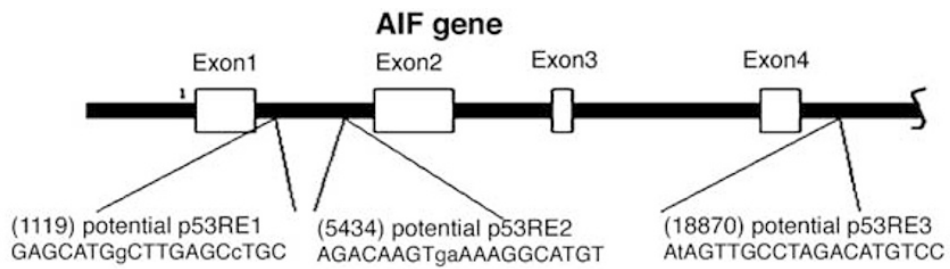

b

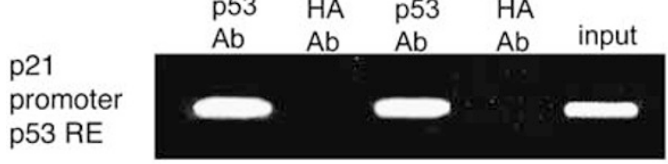

AIF p53 RE1

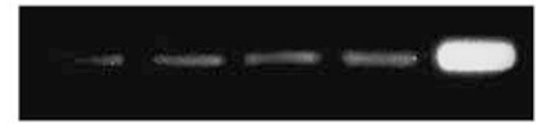

AIF

p53 RE2
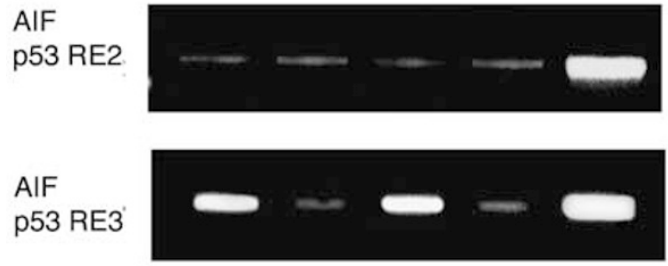

C

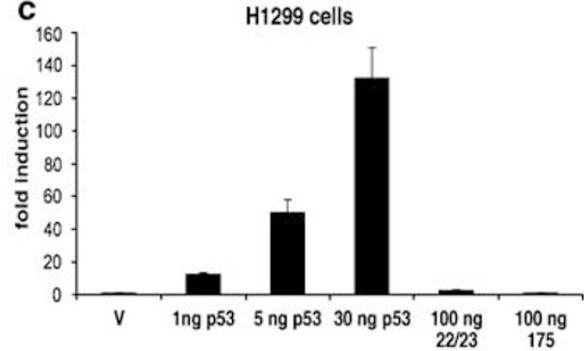

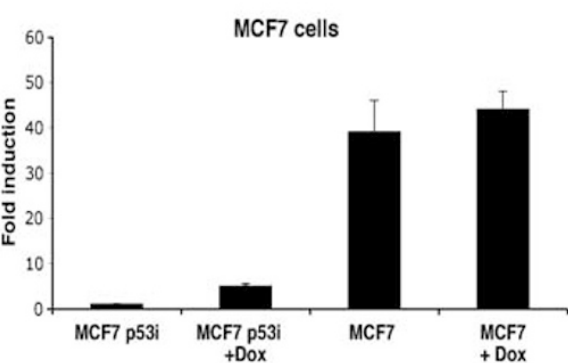

Figure 3 A p53RE resides within the fourth intron of the AIF gene. (a) Schematic representation of the AlF gene. Potential p53RE are indicated. Numbers in parentheses indicate nucleotide positions relative to the transcription start site. (b) HCT116 cells, either untreated or treated with CIS, as well as MCF7 cells and their derivatives whose p53 levels had been knocked down by RNA interference (p53 RNAi) were subjected to chromatin immunoprecipitation with antibodies directed against either p53 or the HA tag (negative control). The precipitated DNA was subjected to PCR amplification using sets of primers specific to the three potential p53 binding sites indicated in (a). The $5^{\prime}$ p53RE of the p $21^{\text {wat1 }}$ gene served as a positive control for p53 binding (top panel). Thirty-two cycles of PCR amplification were performed for each reaction. The input lane contained $0.5 \%$ of the total input chromatin before immunoprecipitation. (c) A 50 bp DNA fragment containing p53RE3 (spanning nucleotides 18 855-18 905, see panel a) was cloned into the promoterless luciferase reporter vector pGL3-basic. Left panel: The reporter plasmid was transiently cotransfected into H1299 cells with increasing amounts of a wild-type p53 expression plasmid (p53) or plasmids encoding either an artificial p53 mutant with a defective transactivation domain, $\mathrm{p} 53,{ }^{22,23}$ or the tumor-derived p53R175H mutant, carrying a nonfunctional DNA-binding domain. Total DNA was kept constant by addition of vector control (pcDNA3). Luciferase activity was determined $48 \mathrm{~h}$ after transfection. V, vector control. Right panel: The above reporter plasmid was transiently transfected into either MCF7 cells or their derivatives knocked down for p53 (p53i). When indicated, $0.4 \mu \mathrm{M}$ doxorubicin (Dox) was added to the culture for $12 \mathrm{~h}$ before harvesting. Values shown represent fold induction relative to the first sample shown on the left side of each panel

was induced in $\mathrm{H} 1299$ cells by $\mathrm{Zn}^{2+}$ and the cells were either treated with $z V A D-f m k$ or left untreated. To increase the rate of apoptosis, some of the cultures were exposed to CIS for $8 \mathrm{~h}$ before being harvested. Large-scale DNA fragmentation was visualized by field inverted gel electrophoresis (FIGE). ${ }^{29}$ The results are shown in Figure $4 \mathrm{~b}$ and quantified in Figure $4 \mathrm{c}$. As shown, distinctive high-molecular-weight DNA fragments, migrating near or slightly ahead of the $50 \mathrm{~kb}$ marker, were clearly observed in cells induced to express wild-type p53 (Figure 4b, lane 4), but such fragments were significantly less abundant when p53 was not present (lane 1). Similarly, although addition of CIS increased overall large-scale DNA fragmentation, the extent of such fragmentation remained higher in p53-expressing cells (lane 5) as compared to p53null cells (lane 2). Treatment with zVAD-fmk caused some further increase in the amount of $50 \mathrm{~kb}$ DNA fragments, probably owing to inhibition of further DNA cleavage by caspase-activated nucleases; nevertheless, the difference between p53-positive and p53-negative cells was maintained. These results are consistent with the conclusion that under conditions where wild-type p53 can promote apoptosis, it induces the production of active AIF that can orchestrate large-scale DNA fragmentation and facilitate caspase-independent cell death. 

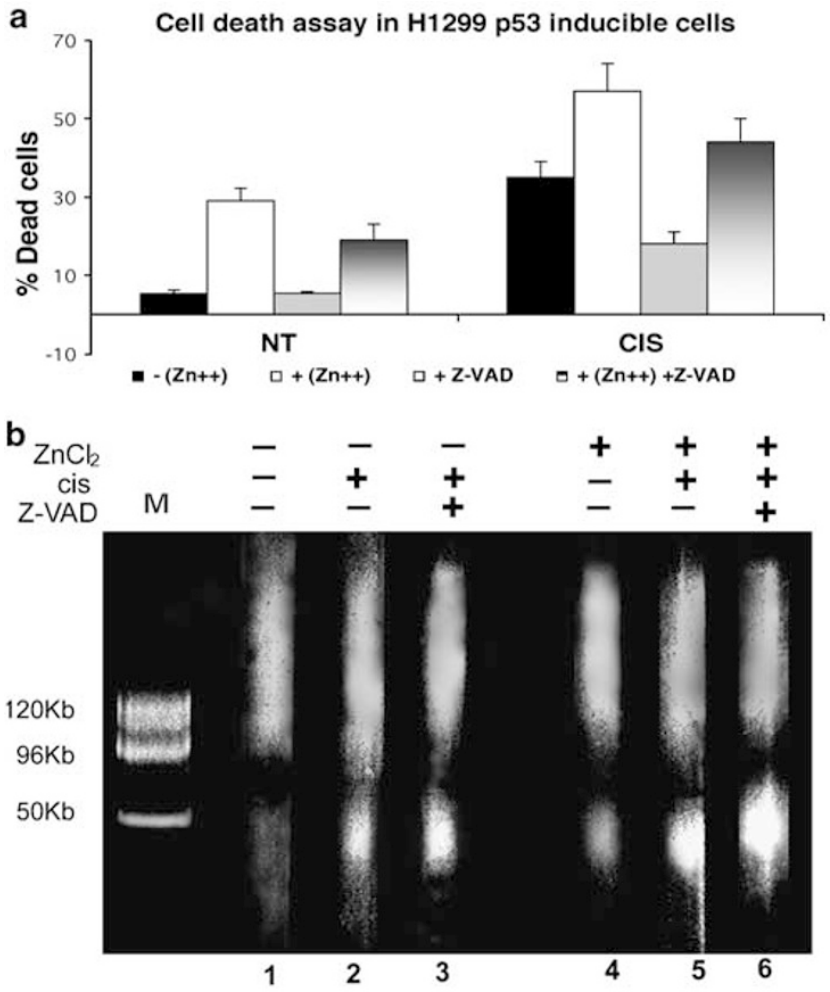

C

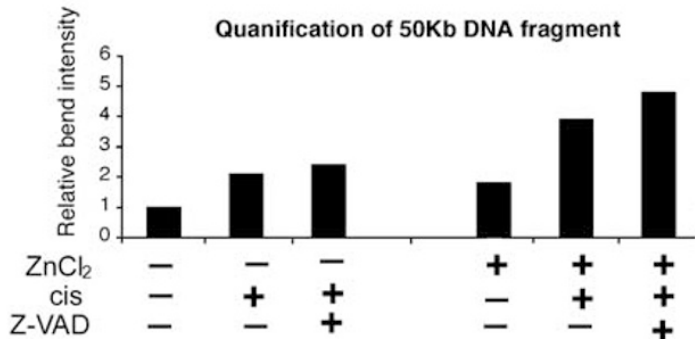

Figure 4 Induction of caspase-independent cell death and large-scale DNA fragmentation by p53. (a) H1299 cells expressing exogenous wild-type p53 under the control of a metallothionein promoter were either incubated with $50 \mu \mathrm{M} \mathrm{ZnCl}_{2}$ for $40 \mathrm{~h}$ to induce p53 $\left(+\mathrm{Zn}^{2+}\right)$ or left untreated. When indicated, $50 \mu \mathrm{M}$ zVADfmk was added to the culture before p53 induction to block caspase activation. Cultures were either treated with $5 \mu \mathrm{g} / \mathrm{ml} \mathrm{ClS}$ for the last $34 \mathrm{~h}$ of the experiment or left untreated (NT). Dead cells were counted by a FACS-based PI exclusion assay. (b) H1299 cells expressing exogenous wild-type p53 under the control of a metallothionein promoter were either incubated with $50 \mu \mathrm{M} \mathrm{ZnCl}$ for $16 \mathrm{~h}$ to induce p53 or left untreated. When indicated, $50 \mu \mathrm{M}$ zVAD-fmk was added to the culture for $24 \mathrm{~h}$. Cultures were either treated with $5 \mu \mathrm{g} / \mathrm{ml} \mathrm{CIS}$ for the last $10 \mathrm{~h}$ of the experiment or left untreated. Pellets containing $1 \times 10^{6}$ cells were embedded in agarose plugs, digested twice with proteinase $\mathrm{K}$ for $24 \mathrm{~h}$ and the DNA contained within the plugs was subjected to field inverted gel electrophoresis (FIGE) on a vertical agarose gel. DNA was visualized by staining with $\mathrm{EtBr}$. Large-scale DNA fragmentation, characteristic of AlF activity, is visible as DNA fragments migrating near or slightly below the $50 \mathrm{~kb}$ marker. (c) Quantification of the data in $(\mathbf{b})$. The regions corresponding to the large $(\sim 50 \mathrm{~kb})$ DNA fragments in each lane were scanned and quantified using the 'Image Gauge V3' software. The result is presented as the relative band intensity after background subtraction, normalized to the signal obtained from lane 1 of (b)

\section{AIF contributes to p53-mediated apoptosis}

To further investigate the possibility that AIF contributes, at least to some extent, to p53-mediated apoptosis, we generated several short hairpin RNA (shRNA) expression plasmids designed to give rise to small interfering RNA (siRNA) directed against AIF. Of the four plasmids tested, two (siRNA1 and siRNA4; Figure 5a) effectively knocked down endogenous AIF protein levels in two independent pools, whereas siRNA2 had no effect at all. Next, H1299 cells harboring zinc-inducible wild-type p53 expression were stably transfected with either a combination of plasmids siRNA1 and siRNA4, which markedly reduced basal as well as p53induced AIF levels (Figure $5 \mathrm{~b}$ ), or plasmid siRNA2 as a negative control. The different cell types were then subjected to a variety of treatments, and cell fate was monitored by two types of assays: quantification of apoptosis by counting Annexin V-positive cells under a microscope (Figure 5c, upper panel), or analysis of cell culture survival by crystal violet staining (lower panel). In the absence of $\mathrm{Zn}^{2+}$, where p53 is not expressed, knock-down of AIF did not affect the cell death in response to CIS or etoposide treatment (Figure $5 \mathrm{c}$, left-hand panels); hence, under these experimental conditions, AIF did not contribute to p53-independent apoptosis. Induction of $\mathrm{p} 53$ expression by addition of $\mathrm{Zn}^{2+}$ caused a modest increase in total apoptosis, owing to the engagement of p53-dependent death pathways. Notably, AIF knock-down now slightly reduced the rate of apoptosis, suggesting that the p53-dependent component of apoptosis in that system was somewhat facilitated by optimal AIF expression. Similar results were obtained when culture survival was assayed with the WST-1 reagent (Supplementary Figure 1). Treatment of parental p53-null $\mathrm{H} 1299$ cells with $\mathrm{Zn}^{2+}$ did not elicit any viability loss (Supplementary Figure 2 ), ruling out a contribution of $\mathrm{Zn}^{2+}$-mediated toxicity to the death of the cells expressing inducible p53. A more significant contribution of endogenous AIF to p53-dependent apoptosis became evident upon inclusion of zVAD-fmk (Figure $5 c$, right-hand panels), which neutralizes caspase-dependent death pathways. As expected, zVAD-fmk decreased the overall rates of apoptosis. Notably, the AIF knock-down cells displayed a significant defect in caspase-independent, p53-dependent apoptosis (Figure 5c, right-hand panels; compare third and fourth bars in each cluster). Together, these findings argue that p53mediated apoptosis, at least its caspase-independent arm, depends in part on the presence of optimal AIF levels. Thus, although AIF is not essential for p53-mediated apoptosis in this system, it obviously contributes significantly to this process.

\section{Discussion}

We report here that AIF gene expression is positively regulated by $\mathrm{p} 53$. Consequently, cells lacking functional p53 tend to produce lower amounts of AIF mRNA and protein. The extent to which AIF expression is modulated by $p 53$ varies in a cell type-dependent manner; whereas it is substantial in some cell types such as MCF7 and HCT116, as well as H1299 cells made to re-express p53, some other cell types exhibit only a modest decrease in AIF expression in the absence of functional p53 (data not shown).

We propose that the induction of AIF expression by $\mathrm{p} 53$ plays a dual role. On the one hand, AIF is a well-documented mediator of cell death following its translocation from the 
a

$$
\begin{array}{lllll}
\text { Control } & \text { SiRNA } 1 & \text { SiRNA } 2 & \text { SiRNA } 3 & \text { SiRNA } 4
\end{array}
$$

AIF

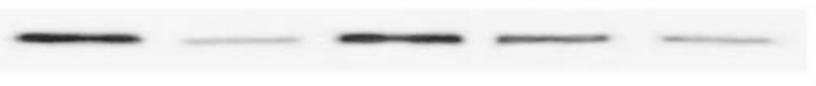

b

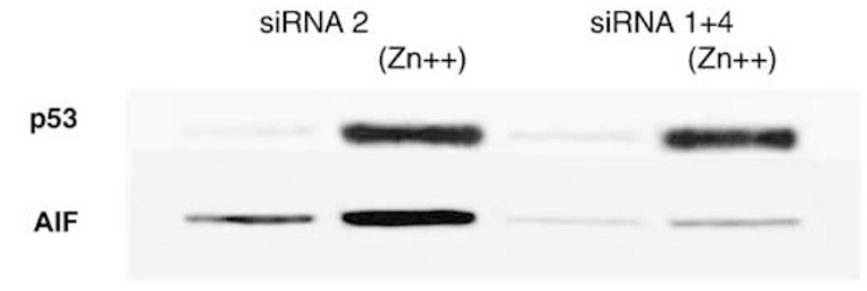

Apoptosis in $\mathrm{H} 1299$ p53 inducible cells

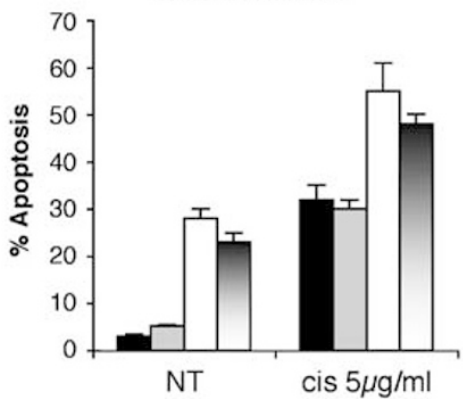

Crystal-Violet assay $\mathrm{H} 1299 \mathrm{p} 53$ inducible cells

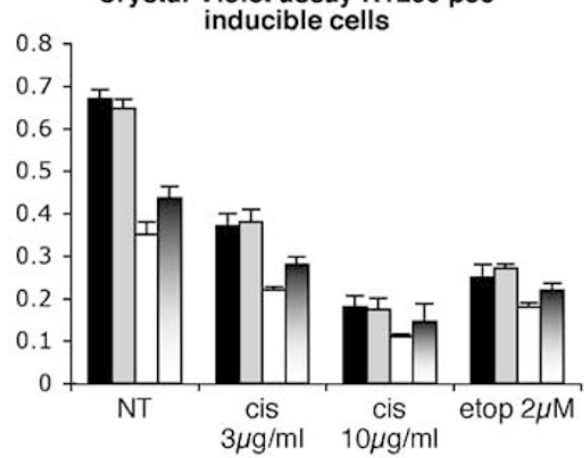

Apoptosis in $\mathrm{H} 1299 \mathrm{p} 53$ inducible cells + Z-VAD

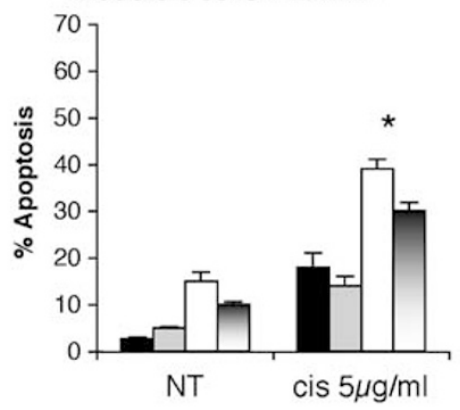

Crystal-Violet assay H1299 p53 inducible cells + Z-VAD

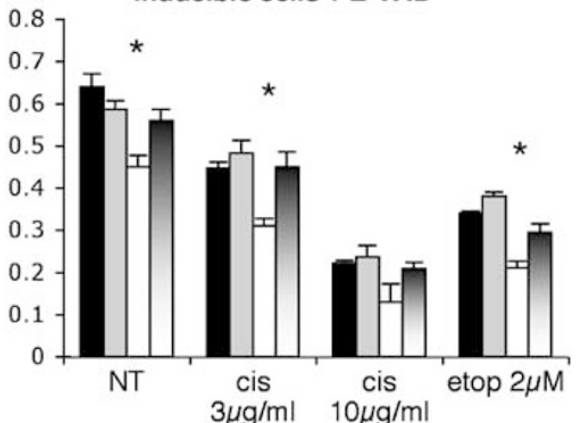

Figure 5 AIF knock-down partially protects cells from p53-mediated apoptosis. (a) H1299 cells expressing exogenous wild-type p53 under the control of a metallothionein promoter were transfected with four different pSilencer-based plasmids expressing AIF-shRNA (siRNA1-4) or empty vector control. Following 10 days of selection in the presence of $0.5 \mu \mathrm{g} / \mathrm{ml}$ puromycin, drug-resistant cells were harvested for Western blot analysis with an AlF-specific polyclonal antibody. (b) H1299 cells with inducible p53 expression were transfected and selected as in (a), using either $5 \mu \mathrm{g}$ of the siRNA2 plasmid per $10 \mathrm{~cm}$ dish or a combination of $2.5 \mu \mathrm{g}$ siRNA1 and $2.5 \mu \mathrm{g}$ of siRNA4 plasmids. Where indicated, $\mathrm{p} 53$ was induced by incubation with $50 \mu \mathrm{M} \mathrm{ZnCl}_{2}$ for $16 \mathrm{~h}$ before cell harvesting. Cell extracts were subjected to SDS-PAGE and Western blot analysis with antibodies directed against p53 or AIF. (c) Upper panels: H1299 cells with inducible p53 expression were transfected and selected as in (a), using either $5 \mu \mathrm{g}$ of the siRNA2 plasmid per $10 \mathrm{~cm}$ dish (siControl) or a combination of $2.5 \mu \mathrm{g}$ siRNA1 and $2.5 \mu \mathrm{g}$ of siRNA4 plasmids (siAIF). Transfected selected cultures were either left untreated (NT) or incubated with $50 \mu \mathrm{M} \mathrm{ZnCl}_{2}\left(+\mathrm{Zn}^{2+}\right)$ for $20 \mathrm{~h}$ to induce $\mathrm{p} 53$ expression. When indicated, CIS was added for $20 \mathrm{~h}$ before cell harvesting. In the right panel, $50 \mu \mathrm{M}$ zVAD-fmk was added to the cultures $2 \mathrm{~h}$ before $\mathrm{p} 53$ induction. Apoptosis levels were determined by staining cells for Annexin $\mathrm{V}$ and counting positive cells under the microscope. The graph shows a mean with standard deviation of three separate experiments. The difference between cells expressing AIF shRNA and those expressing control shRNA was found to be significant $\left(P<0.05\right.$; indicated by ${ }^{*}$ ). Lower panels: Cells were transfected and selected as above, 4000 cells per well were seeded in 96-well dishes and were either left untreated (NT) or incubated with $50 \mu \mathrm{M} \mathrm{ZnCl}_{2}\left(\mathrm{Zn}^{2+}\right)$ for $32 \mathrm{~h}$ to induce p53 expression. When indicated, either etoposide (etop) or CIS was added for $24 \mathrm{~h}$ before cell harvesting. In the right panel, $50 \mu \mathrm{M}$ zVAD-fmk was added to the cultures $2 \mathrm{~h}$ before p53 induction. Cells were stained with crystal violet and optical density was measured at $595 \mathrm{~nm}$. Means plus standard deviations, based on triplicate samples, are shown

mitochondria to the nucleus. Cells harboring functional p53 will constitutively contain higher levels of mitochondrial AIF. Upon exposure to apoptogenic stress, such cells would be able to mobilize larger amounts of AIF to the nucleus, thereby giving rise to more efficient nuclear demise and cell death. In this manner, p53-positive cells will become more susceptible to apoptotic stimuli that engage the mitochondrial death pathway and trigger AIF release. The contribution of AIF to p53-mediated apoptosis is expected to be more pronounced under conditions where apoptosis proceeds in the absence of caspase activation, and we provide evidence suggesting that this is indeed the case. On the other hand, through enabling proper assembly and function of mitochondrial respiratory complex I, AIF also possesses an important cytoprotective function, defending the cell against oxidative damage and other types of stress. ${ }^{15}$ When AIF is deficient, oxidative 
phosphorylation is severely compromised, and this can lead to loss of viability of cells that are highly dependent on mitochondrial ATP production. ${ }^{14}$ Defects in respiratory complex I may compromise its contribution to peroxide detoxification, ${ }^{16,17}$ providing an additional mechanism whereby AIF can enhance the cellular defense against oxidative damage. Hence, when not exposed to acute apoptogenic stress, cells containing functional wild-type p53 should benefit from the cytoprotective effect of AIF in the mitochondria. Both roles of AIF may contribute to its tumor suppressor function, the first by facilitating the apoptotic execution of cells harboring major cancer-promoting lesions, and the second by protecting cells from accumulating such lesions through establishment of a more effective buffer against oxidative damage.

Unlike many other p53 target genes, the expression of which is mainly induced by p53 in response to oncogenic stress, AIF is regulated by p53 mainly at the level of basal gene expression. In fact, activation of p53 by genotoxic stress has rather little impact on AIF levels. It should be kept in mind, however, that standard tissue culture conditions are not devoid of stress. It remains to be determined to what extent the apparent effect of p53 on 'basal' AIF levels is due to such 'culture shock', ${ }^{30}$ particularly the chronic mild oxidative stress that is often associated with these conditions. ${ }^{31}$

If p53 indeed controls basal AIF levels also in more physiological in vivo contexts, this may serve to accelerate p53-dependent apoptosis when appropriate apoptogenic signals are encountered. It is conceivable that a multi-step sequence of events including p53 accumulation, induction of AIF transcription and translation, localization of AIF to the mitochondria and finally its translocation to and accumulation in the nucleus may impose severe delays on the efficient execution of the apoptotic response. In contrast, continuous presence of abundant AIF in the mitochondria, well before the cells encounter severe stress, will ensure a much faster response. In this regard, the direct action of p53 on the mitochondrial outer membrane ${ }^{32,33}$ might exert a synergistic effect by enabling the rapid release of AIF from the mitochondria.

However, it is plausible that the main purpose of AIF regulation by $\mathrm{p} 53$ is not to facilitate apoptosis but rather to provide a cytoprotective function, through its contribution to respiratory complex I assembly. This conjecture is supported by the finding that p53 controls basal expression levels of AIF. Remarkably, a similar picture is seen with several other p53 target genes of which products exert cytoprotective effects, including $\mathrm{MnSOD}^{34}$ and glutathione peroxidase. ${ }^{35}$ Thus, p53 may perform an important maintenance role in non-stressed cells. Such role may comprise several functional arms, affecting on the one hand DNA repair, through induction of repair genes as well as via a direct role of p53 in some DNA repair processes, ${ }^{36}$ and on the other hand prevention of severe oxidative damage through induction of genes such as MnSOD, GPx and members of the sestrin family of cysteine sulfinyl reductases. ${ }^{37,38}$ We also report the identification of a functional p53RE residing within the fourth intron of the AIF gene. The features of this p53RE may account for the distinct mode of regulation of AIF gene expression. On the one hand, the AIF p53RE is almost a perfect match to the consensus site as defined by el-Deiry et al., ${ }^{26}$ which is likely to mediate high-affinity binding and efficient recruitment of p53 even in cells harboring low endogenous p53 levels. On the other hand, its large distance from the transcription initiation site may explain why this gene is upregulated only mildly (2-4-fold) by p53. In sum, AIF represents a unique type of p53 target gene, the products of which play a cytoprotective role under conditions of mild stress, while contributing to cell death under conditions of severe stress. Such genes enable p53 to perform quality control at multiple levels. It remains to be established how many other p53 target genes follow a similar paradigm.

\section{Materials and Methods}

\section{Cell lines}

The $\mathrm{H} 1299$ human non-small cell lung cancer cell line was maintained in RPMI 1640 medium supplemented with 10\% fetal calf serum and antibiotics. The human breast cancer cell line MCF7 stably expressing shRNA targeting p53, as well as its vector control line, was a gift from $\mathrm{Dr} R$ Agami (Netherlands Cancer Institute). MCF7 cells were grown in Dulbecco's modified Eagle's medium supplemented with $10 \%$ fetal calf serum, $2 \mathrm{mM}$ L-glutamine and antibiotics. The HCT116 colon carcinoma cell line and its p53 knockout derivative were a gift from Dr B Vogelstein (The Johns Hopkins University, Baltimore, MD, USA), and were maintained in McCoy's medium supplemented with $10 \%$ fetal calf serum and antibiotics. All cell lines were grown at $37^{\circ} \mathrm{C}$ in a humidified atmosphere of $5 \% \mathrm{CO}_{2}$ in air.

\section{Plasmids}

Expression plasmids for wild-type human p53 and mutants L22Q/W23S andR175H, were gifts from $\mathrm{Dr} \mathrm{C}$ Harris. The reporter construct containing the AIF p53RE3 was constructed by inserting a corresponding synthetic 50 bp oligonucleotide into the PGL-3 basic (Promega, Madison, WI, USA) vector. Plasmids encoding shRNA were constructed in the pSuper-RetroPuro vector as described. ${ }^{39}$ The following 19-bp AIF sequences were targeted: RNAi-1, AGACACTGCGATTCAAACA; RNAi-2, GAAGTCTGTC TGCCATTGA; RNAi-3, GGTAGAAACTGACCACATA; and RNAi-4, GAC AACCCCAAATCTGCCA.

\section{Real-time reverse transcription-polymerase chain reaction analysis}

Total RNA was extracted using the Trireagent kit (Macherey Nagel, Germany). Two micrograms of each RNA sample was reverse transcribed using Moloney murine leukemia virus reverse transcriptase (Promega, Madison, WI, USA) and random hexamer primers. Real-time PCR was performed on an $A B I 7000$ machine (Applied Biosystems) using Sybr Green PCR mastermix (Applied Biosystems), AlF-specific primers (sense, GATTGCAACAGGAGGTACTCCAAGA; antisense, GATTTGACTTCCC GTGAAATCTTCTC) and p53-specific primers (sense, CCCAAGCAATG GATGATTTGA; antisense, GGCATTCTGGGAGCTCATCT). cDNA levels were normalized to GAPDH amplified with appropriate primers (sense, ACCACAGTCGCCATCAC; antisense, TCCACCACCCTGTTGCTGTA.

\section{Western blot analysis}

For Western blotting of p53 and AIF proteins, $50 \mu \mathrm{g}$ of total cell lysate was separated on $10 \%$ SDS-PAGE and transferred to a nitrocellulose 
membrane. Membranes were blocked overnight in 5\% dry skimmed milk in PBS/Tween, and p53 was detected using a polyclonal antibody produced in our laboratory. For detection of AIF, a polyclonal antibody (Anti-AIFct, ProSci Inc.) was used. The protein-antibody complexes were detected using a horseradish peroxidase-conjugated secondary antibody (Roche Applied Science) using the enhanced chemiluminescence ECL system (Amersham Biosciences). Equal loading was verified in each experiment by Ponceau red staining.

\section{Luciferase assays}

Cells were seeded in 24-well culture dishes. Each well was transfected with a reporter plasmid expressing the firefly luciferase gene under the transcriptional control of the AIF p53RE3, together with increasing amounts of various expression plasmids and $\beta$-galactosidase ( $\beta$-gal) plasmid. Luciferase activity was assayed $48 \mathrm{~h}$ post-transfection. Each plasmid combination was transfected into three identical wells. Luciferase assays were performed using (D)-luciferin (Roche). Luminescence was determined with the aid of a Rosys-Anthos Lucy 3 luminometer. Luciferase values were normalized to $\beta$-gal activity.

\section{Chromatin immunoprecipitation}

Formaldehyde (Merck) was added directly to the cell culture medium at a final concentration of $1 \%$. Fixation proceeded at room temperature for $10 \mathrm{~min}$ and was stopped by the addition of glycine to a final concentration of $0.125 \mathrm{M}$. Plates were rinsed with cold PBS, incubated with $10 \mathrm{ml}$ of $20 \%$ trypsin-EDTA (GIBCO) in PBS and then scraped. Cells were rinsed three

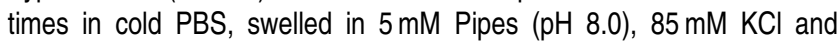
protease inhibitors cocktail on ice for $20 \mathrm{~min}$ and then disrupted with a Dounce homogenizer. Nuclei were collected by centrifugation at 4000 r.p.m., resuspended in nuclei lysis buffer and incubated on ice for $10 \mathrm{~min}$. Samples were sonicated on ice to an average length of $1000 \mathrm{bp}$ and then microfuged at 14000 r.p.m. The chromatin solution was precleared with the addition of protein $A$ beads for $2 \mathrm{~h}$ at $4{ }^{\circ} \mathrm{C}$. Precleared chromatin from $2.5 \times 10^{7}$ cells was diluted $1: 5$ in dilution buffer $(0.01 \%$ SDS, $1 \%$ Triton X-100, 1.2 mM EDTA, $167 \mathrm{mM} \mathrm{NaCl}$, protease inhibitors cocktail) and incubated with $30 \mu$ protein $A$ beads crosslinked by DMP to anti-p53 polyclonal $\mathrm{Ab}$ or to anti-HA antibody, and rotated at $4{ }^{\circ} \mathrm{C}$ for $12 \mathrm{~h}$. Immunoprecipitates were washed twice with dilution buffer, twice with wash buffer and once with TE. After treatment with $10 \mu \mathrm{g}$ RNase A per sample for $30 \mathrm{~min}$, followed by $30 \mu \mathrm{g}$ of proteinase $\mathrm{K}$ for $2 \mathrm{~h}$ at $50^{\circ} \mathrm{C}$, crosslinks were reversed by incubation at $65^{\circ} \mathrm{C}$ overnight. DNA samples were extracted using mini-columns PCR clean-up preps (Promega). PCR reactions contained $2 \mu \mathrm{l}$ of immunoprecipitated or diluted total input, $50 \mathrm{ng}$ of each primer, AIF p53RE1 forward (5'-GAATTCGGGTCTCTTCCCA GT), AIF p53RE1 reverse (5'-TTGCCCCCATGAAGTAACG), AIF p53RE2 forward (5'- GGAGTAAGTTGGCTTTTCCATGTT), AIF p53RE2 reverse (5'- CTCCCAAACCTTTCTCCCCATA), AIF p53RE3 forward (5'- GATT ACAGGCGTGAGCCACTG), AIF p53RE2 reverse (5'- TGCCTGCT AGGCTGTCAAAGA), and Ready mix PCR mastermix (Promega) in a total volume of $20 \mu \mathrm{l}$. After 30 cycles of amplification, PCR products were run on a $2 \%$ agarose gel and analyzed by ethidium bromide staining.

\section{DNA field inverted gel electrophoresis}

DNA was prepared from agarose plugs $\left(1 \times 10^{6}\right.$ cells $)$ digested twice with proteinase $\mathrm{K}\left(1 \mathrm{mg} / \mathrm{ml} ; 50^{\circ} \mathrm{C} ; 12 \mathrm{~h}\right)$ in NDS buffer $(0.5 \mathrm{M} \mathrm{EDTA}, 10 \mathrm{mg} / \mathrm{ml}$ lauroyl sarcosine), washed in TBE $\times 0.5$, followed by electrophoresis using a vertical gel chamber, a power supply and a PC 750 pulse controller
(Hoefer Scientific Instruments, UK) as described. ${ }^{29}$ Molecular weight standards were from Bio-Rad (Yeast chromosomes) and Appligene (Raoul; Illkirch, France).

\section{Apoptosis and viability assays}

Apoptosis was quantified with the aid of an Annexin V staining kit. Adherent $\mathrm{H} 1299$ cells were directly stained on Petri dishes with Annexin VFITC (1:100 dilution; from the Annexin V-FITC kit, Immunotech, Beckman-Coulter) and propidium iodide (PI, $12.5 \mathrm{~g} / \mathrm{ml}$; Immunotech, Beckman-Coulter) for 10 min on ice in the dark, in binding buffer containing $10 \mathrm{mM}$ Hepes- $\mathrm{NaOH}, \mathrm{pH} 7.4,140 \mathrm{mM} \mathrm{NaCl}, 2.5 \mathrm{mM} \mathrm{CaCl}_{2}$ and analyzed within $1 \mathrm{~h}$ under a fluorescence microscope.

Alternatively, cell death was monitored by a FACS-based PI exclusion assay, as described. ${ }^{40}$

To monitor culture survival, H1299 cells were seeded in a 96-well culture dish at 5000 cells/well in $100 \mu \mathrm{l}$ of serum-containing medium and incubated at $37^{\circ} \mathrm{C}$. Changes in cell number and viability were quantified using either the WST-1 kit (Roche) or a crystal violet colorimetric assay. For crystal violet staining, a solution containing $0.5 \mathrm{~g}$ crystal violet, $0.85 \mathrm{~g}$ $\mathrm{NaCl}, 5 \mathrm{ml} 10 \%$ formal saline, $50 \mathrm{ml}$ absolute ethanol and $45 \mathrm{ml}$ of distilled water was prepared; $100 \mu \mathrm{l}$ of medium was gently aspirated from each well and replaced by an equal volume of the colorimetric assay mixture and incubated at room temperature for $10 \mathrm{~min}$. This mixture allowed simultaneous fixation of cells and penetration of crystal violet into the living cells. After washing three times in PBS, optical density was read at $595 \mathrm{~nm}$ using a spectrophotometric plate reader.

\section{Statistical analysis}

Statistical analyses were carried out by Student's $t$-test. Statistical significance was defined as $P<0.05$.

\section{Acknowledgements}

This research was supported by a Center of Excellence grant from the Flight Attendant Medical Research Institute (FAMRI), EC FP5 Grant QLK3-CT-2002-01956, EC FP6 Grant LSHC-CT-2004-503576, Grant R37 CA40099 from the National Cancer Institute and Yad Abraham Center for Cancer Diagnosis and Therapy. This publication reflects the authors' views and not necessarily those of the European Community. The EC is not liable for any use that may be made of the information contained herein. VR is the incumbent of the Norman and Helen Asher Professorial Chair Cancer Research at the Weizmann Institute.

\section{References}

1. Pietenpol JA, Tokino T, Thiagalingam S, el-Deiry WS, Kinzler KW and Vogelstein B (1994) Sequence-specific transcriptional activation is essential for growth suppression by p53. Proc. Natl. Acad. Sci. USA 91: 1998-2002.

2. Vogelstein B, Lane D and Levine AJ (2000) Surfing the p53 network. Nature 408: 307-310.

3. Oren M (2003) Decision making by p53: life, death and cancer. Cell Death Differ. 10: 431-442.

4. Miyashita T and Reed JC (1995) Tumor suppressor p53 is a direct transcriptional activator of the human bax gene. Cell 80: 293-299.

5. Nakano K and Vousden KH (2001) PUMA, a novel proapoptotic gene, is induced by p53. Mol. Cell 7: 683-694. 
6. Gao CF, Ren S, Zhang L, Nakajima T, Ichinose S, Hara T, Koike $\mathrm{K}$ and Tsuchida N (2001) Caspase-dependent cytosolic release of cytochrome $c$ and membrane translocation of Bax in p53-induced apoptosis. Exp. Cell Res. 265: $145-151$.

7. Soengas MS, Alarcon RM, Yoshida H, Giaccia AJ, Hakem R, Mak TW and Lowe SW (1999) Apaf-1 and caspase-9 in p53-dependent apoptosis and tumor inhibition. Science 284: 156-159.

8. Godefroy N, Lemaire C, Renaud F, Rincheval V, Perez S, Parvu-Ferecatu I, Mignotte B and Vayssiere $\mathrm{JL}$ (2004) p53 can promote mitochondria- and caspase-independent apoptosis. Cell Death Differ. 11: 785-787.

9. Johnson MD, Xiang H, London S, Kinoshita $\mathrm{Y}$, Knudson M, Mayberg M, Korsmeyer SJ and Morrison RS (1998) Evidence for involvement of Bax and p53, but not caspases, in radiation-induced cell death of cultured postnatal hippocampal neurons. J. Neurosci. Res. 54: 721-733.

10. Resnick-Silverman L, St Clair S, Maurer M, Zhao K and Manfredi JJ (1998) Identification of a novel class of genomic DNA-binding sites suggests a mechanism for selectivity in target gene activation by the tumor suppressor protein p53. Genes Dev. 12: 2102-2107.

11. Punj V and Chakrabarty AM (2003) Redox proteins in mammalian cell death: an evolutionarily conserved function in mitochondria and prokaryotes. Cell Microbiol. 5: 225-231.

12. Susin SA, Lorenzo HK, Zamzami N, Marzo I, Snow BE, Brothers GM, Mangion J, Jacotot E, Costantini P, Loeffler M, Larochette N, Goodlett DR, Aebersold R Siderovski DP, Penninger JM and Kroemer G (1999) Molecular characterization of mitochondrial apoptosis-inducing factor. Nature 397 441-446.

13. Miramar MD, Costantini $P$, Ravagnan L, Saraiva $L M$, Haouzi $D$, Brothers $G$ Penninger JM, Peleato ML, Kroemer G and Susin SA (2001) NADH oxidase activity of mitochondrial apoptosis-inducing factor. J. Biol. Chem. 276: 16391-16398

14. Vahsen N, Cande C, Briere JJ, Benit P, Joza N, Larochette N, Mastroberardino PG, Pequignot MO, Casares N, Lazar V, Feraud O, Debili N, Wissing S, Engelhardt S, Madeo F, Piacentini M, Penninger JM, Schagger H, Rustin P and Kroemer G (2004) AIF deficiency compromises oxidative phosphorylation. EMBO J. 23: 4679-4689 (E-pub 2004 Nov 4).

15. Urbano A, Lakshmanan U, Choo PH, Kwan JC, Ng PY, Guo K, Dhakshinamoorthy S and Porter A (2005) AIF suppresses chemical stressinduced apoptosis and maintains the transformed state of tumor cells. EMBO J. 24: 2815-2826

16. Atorino L, Silvestri L, Koppen M, Cassina L, Ballabio A, Marconi R, Langer $T$ and Casari $G$ (2003) Loss of m-AAA protease in mitochondria causes complex I deficiency and increased sensitivity to oxidative stress in hereditary spastic paraplegia. J. Cell Biol. 163: 777-787 (E-pub 2003 Nov 17).

17. Zoccarato $F$, Cavallini $L$ and Alexandre A (2004) Respiration-dependent removal of exogenous $\mathrm{H} 2 \mathrm{O} 2$ in brain mitochondria: inhibition by $\mathrm{Ca} 2+$. J. Biol. Chem. 279: 4166-4174 (E-pub 2003 Nov 20).

18. Klein JA, Longo-Guess CM, Rossmann MP, Seburn KL, Hurd RE, Frankel WN Bronson RT and Ackerman SL (2002) The harlequin mouse mutation downregulates apoptosis-inducing factor. Nature 419: 367-374.

19. Cande C, Cecconi F, Dessen P and Kroemer G (2002) Apoptosis-inducing factor (AIF): key to the conserved caspase-independent pathways of cell death? J. Cell Sci. 115: 4727-4734.

20. Cregan SP, Dawson VL and Slack RS (2004) Role of AIF in caspasedependent and caspase-independent cell death. Oncogene 23: 2785-2796.

21. Ye H, Cande C, Stephanou NC, Jiang S, Gurbuxani S, Larochette N, Daugas E, Garrido C, Kroemer G and Wu H (2002) DNA binding is required for the apoptogenic action of apoptosis inducing factor. Nat. Struct. Biol. 9: 680-684.

22. Susin SA, Lorenzo HK, Zamzami N, Marzo I, Brenner C, Larochette N, Prevost MC, Alzari PM and Kroemer G (1999) Mitochondrial release of caspase-2 and9 during the apoptotic process. J. Exp. Med. 189: 381-394.
23. Cande C, Vahsen N, Garrido C and Kroemer G (2004) Apoptosis-inducing factor (AIF): caspase-independent after all. Cell Death Differ. 11: 591-595.

24. Loeffler M, Daugas E, Susin SA, Zamzami N, Metivier D, Nieminen AL, Brothers G, Penninger JM and Kroemer G (2001) Dominant cell death induction by extramitochondrially targeted apoptosis-inducing factor. FASEB J. 15: 758-767.

25. Seth R, Yang C, Kaushal V, Shah SV and Kaushal GP (2005) p53-dependent caspase-2 activation in mitochondrial release of apoptosis-inducing factor and its role in renal tubular epithelial cell injury. J. Biol. Chem. 280: 31230-31239.

26. el-Deiry WS, Kern SE, Pietenpol JA, Kinzler KW and Vogelstein B (1992) Definition of a consensus binding site for p53. Nat. Genet. 1: 45-49.

27. Cawley S, Bekiranov S, Ng HH, Kapranov P, Sekinger EA, Kampa D, Piccolboni A, Sementchenko V, Cheng J, Williams AJ, Wheeler R, Wong B, Drenkow J, Yamanaka M, Patel S, Brubaker S, Tammana H, Helt G, Struhl K and Gingeras TR (2004) Unbiased mapping of transcription factor binding sites along human chromosomes 21 and 22 points to widespread regulation of noncoding RNAs. Cell 116: 499-509.

28. Fei P, Wang W, Kim SH, Wang S, Burns TF, Sax JK, Buzzai M, Dicker DT, McKenna WG, Bernhard EJ and El-Deiry WS (2004) Bnip3L is induced by p53 under hypoxia, and its knock-down promotes tumor growth. Cancer Cell 6: 597-609.

29. Brown DG, Sun XM and Cohen GM (1993) Dexamethasone-induced apoptosis involves cleavage of DNA to large fragments prior to internucleosomal fragmentation. J. Biol. Chem. 268: 3037-3039.

30. Sherr CJ and DePinho RA (2000) Cellular senescence: mitotic clock or culture shock? Cell 102: 407-410.

31. Schweder T and Hecker M (2004) Monitoring of stress responses. Adv. Biochem. Eng. Biotechnol. 89: 47-71.

32. Schuler M and Green DR (2001) Mechanisms of p53-dependent apoptosis. Biochem. Soc. Trans. 29 (Part 6): 684-688.

33. Mihara M, Erster S, Zaika A, Petrenko O, Chittenden T, Pancoska P and Moll UM (2003) p53 has a direct apoptogenic role at the mitochondria. Mol. Cell 11: 577-590.

34. Pani G, Bedogni B, Anzevino R, Colavitti R, Palazzotti B, Borrello S and Galeotti $T$ (2000) Deregulated manganese superoxide dismutase expression and resistance to oxidative injury in p53-deficient cells. Cancer Res. 60: 4654-4660.

35. Hussain SP, Amstad P, He P, Robles A, Lupold S, Kaneko I, Ichimiya M, Sengupta S, Mechanic L, Okamura S, Hofseth LJ, Moake M, Nagashima M, Forrester KS and Harris CC (2004) p53-induced up-regulation of MnSOD and GPx but not catalase increases oxidative stress and apoptosis. Cancer Res. 64: 2350-2356.

36. Rubbi CP and Milner J (2003) p53-guardian of a genome's guardian? Cell Cycle 2: 20-21.

37. Budanov AV, Sablina AA, Feinstein E, Koonin EV and Chumakov PM (2004) Regeneration of peroxiredoxins by p53-regulated sestrins, homologs of bacterial AhpD. Science 304: 596-600.

38. Sablina AA, Budanov AV, llyinskaya GV, Agapova LS, Kravchenko JE and Chumakov PM (2005) The antioxidant function of the p53 tumor suppressor. Nat. Med. 11: 1306-1313.

39. Brummelkamp TR, Bernards R and Agami R (2002) A system for stable expression of short interfering RNAs in mammalian cells. Science 296: 550-553 (E-pub 2002 Mar 21).

40. Zalcenstein A, Stambolsky P, Weisz L, Muller M, Wallach D, Goncharov TM, Krammer PH, Rotter V and Oren M (2003) Mutant p53 gain of function: repression of $\mathrm{CD} 95$ (Fas/APO-1) gene expression by tumor-associated p53 mutants. Oncogene 22: 5667-5676.

Supplementary Information accompanies the paper on Cell Death and Differentiation website (http://www.nature.com/cdd) 